\title{
UMA REFLEXÃO SOBRE A SAÚDE DO TRABALHADOR DE ENFERMAGEM E OS AVANÇOS DA LEGISLAÇÃO TRABALHISTA*
}

[A retrospective on nursing professionals' health and the advancement of Brazilian labor legislation]

\author{
Leila Maria Mansano Sarquis** \\ Eliane Bezerra da Silva Cruz*** \\ Mônica Hausmann*** \\ Vanda Elisa Andres Felli**** \\ Marina Peduzzi ${ }^{* \star * * *}$
}

RESUMO: Neste artigo apresenta-se uma retrospectiva da Legislação Trabalhista no Brasil e suas relações para a saúde dos trabalhadores de enfermagem com base na revisão da literatura. Verificou-se que desde 1904 existia a tentativa de criar uma legislação especial para acidentes causados pelo trabalho, mas a primeira Lei só foi editada em 1919 sendo que, esta e as seguintes foram mudando a concepção do acidente de trabalho e suas implicações à saúde do trabalhador e no que diz respeito à inserção no processo de trabalho. Relata-se as transformações ocorridas na Legislação Trabalhista, suas implicações e adequações com o intuito de maximizar a saúde do trabalhador. A partir de determinações legais os responsáveis pelos serviços médicos das empresas foram obrigados a se preocupar com os resultados de seus programas ocupacionais.

PALAVRAS-CHAVE: Legislação trabalhista; Saúde ocupacional; Enfermagem.

\footnotetext{
*Estudo desenvolvido na disciplina ENO 5813 - Estudo das relação saúde e trabalho de enfermagem do Programa de Pós Graduação da Escola de Enfermagem da USP em 2004.

**Enfermeira, doutoranda do Programa de Pós-graduação na área de Concentração em Administração de Enfermagem pela EEUSP, bolsista do CNPq.

***Enfermeiras, mestrandas do Programa de Pós-graduação na área de Concentração em Administração de Enfermagem pela EEUSP.

****Enfermeira. Profa. Associada do Departamento de Orientação

Profissional da Escola de Enfermagem da Universidade de São Paulo.

${ }^{* * * * \star}$ Enfermeira. Profa. Doutora do Departamento de Orientação

Profissional da Escola de Enfermagem da Universidade de São Paulo.
}

\section{INTRODUÇÃO E OBJETIVO}

O termo saúde do trabalhador refere-se a um campo do saber que visa compreender as relações entre trabalho e processo saúde-doença. Nesta acepção, considera a saúde e a doença como processos dinâmicos, estreitamente articulados com os modos de desenvolvimento produtivo da humanidade em determinado momento histórico. Parte do princípio de que a forma de inserção dos indivíduos nos espaços de trabalho, contribuem decisivamente para formas especificas de adoecer e morrer (BRASIL, 2002).

Analisando a saúde do trabalhador no contexto da enfermagem, através dos tempos, é possível verificar que estes trabalhadores estão expostos a várias cargas que comprometem a saúde, gerando índices elevados de acidentes de trabalho e doenças relacionadas ao trabalho. A partir dessa percepção, faz-se necessário compreender melhor essa problemática e buscar na legislação trabalhista ressaltando as questões da saúde do profissional de enfermagem.

Esta análise permite verificar que a legislação trabalhista avançou grandes passos a partir da promulgação da Constituição Federal, na qual as leis orgânicas foram se atualizando e resultaram em exigências legais transformadas em portarias, leis e decretos que se modificaram se completando e se alterando com o objetivo de adequar a saúde do trabalhador ao ambiente de trabalho. 
Assim, o objetivo deste artigo é fazer uma reflexão teórica sobre a problemática de saúde do trabalhador de enfermagem, analisando o respaldo da legislação trabalhista voltada para a saúde do trabalhador.

\section{A Saúde do trabalhador de enfermagem}

Os estudos que enfocam a relação saúdetrabalho de enfermagem nas instituições de saúde começaram a ser realizados na década de 70 e foram incrementados a partir da década de 80 . Observa-se que a maior parte destes trabalhos fundamentavam-se na corrente filosófica do positivismo. Somente a partir da década de 90 são implementados estudos utilizando o materialismo histórico dialético. (SILVA VEF, 1996).

Desde os primeiros estudos, está demonstrado que a saúde do trabalhador de enfermagem é comprometida. Este comprometimento, em parte, conforme afirma Marziale (1990), pode ser detectado através da elevada incidência de acidentes de trabalho e doenças profissionais.

Alguns destes estudos, desenvolvidos em nosso País, a partir da década de 1980, permitem situar e contextualizar a problemática de saúde vivenciada pelos trabalhadores de saúde entre eles os trabalhadores de enfermagem como os estudos realizados por Silva (1988), Barbosa (1989), Marziale (1990), Alexandre (1993), Marziale (1995), Souza (1995), Silva A (1996 ), Silva VEF (1996 ), Alexandre et al (1996), Benatti (1997), Brevidelli (1997), Faria; Silva (1999), Farias (1999), Souza (1999), Pedrosa (1999), Sarquis (1999), Chamorro (1999), Sarquis; Felli (2000); Basso (1999), Porto (1999), Souza (1999), Balsamo (1999), Lacerda (2000), Brasil, Steffens, Lorenzo (2001), Pivetta, Machado , Araujo, (2001), Balsamo (2002), Rodrigues (2003), Reis, Gir, Canini (2004) e Sailer (2004). Nesses estudos, os autores abordam a saúde do trabalhador e a sua relação com o trabalho.

A pesquisa realizada por Silva (1988) com os trabalhadores de enfermagem caracterizou que o risco ocupacional do acidente de trabalho é elevado. Conclui que devem ser elaborados programas de orientação para os trabalhadores de enfermagem, prevenindo assim, a exposição desses trabalhadores aos riscos ocupacionais.
O trabalho realizado por Barbosa (1989), teve como objetivo identificar os riscos químicos ocupacionais a que estão expostos os trabalhadores em ambientes hospitalares. Os resultados encontrados mostram que os trabalhadores de enfermagem estão expostos aos riscos químicos em até $35,9 \%$ e sugere que há necessidade de educação do trabalhador, numa visão prevencionista, em relação aos riscos ocupacionais, assim como uma reestruturação dos currículos das escolas que formam estes profissionais de saúde.

No enfoque da ergonomia, Marziale (1990) refere que toda situação de trabalho comporta aspectos de ordem material, organizacional e humana que necessitam ser avaliados individualmente, a fim de serem encontradas condições para a adaptação entre o homem e o trabalho.

Gelbcke (1991) aborda o processo de trabalho da equipe de enfermagem, de um hospital universitário, correlacionando a produção com as cargas que variam de intensidade e espécie. Refere que esta carga de trabalho transforma-se em desgaste, tanto físico quanto mental, manifestado pela doença ou sintomatologia. Estas cargas, ainda, podem desencadear acidentes em ambiente de trabalho.

Alexandre (1993) em seu estudo sobre a ergonomia aplicada ao trabalho visualizou claramente que a ocorrência de cervicodorsolombalgias em trabalhadores de enfermagem está correlacionada com a inadequação de equipamentos utilizados nas atividades de enfermagem.

Souza (1995), constatou o alto risco ocupacional dos trabalhadores de enfermagem decorrente do não cumprimento das normas de segurança. Em posterior pesquisa, ainda na abordagem ergonômica, Marziale (1995) analisa as condições ergonômicas da situação de trabalho do pessoal de enfermagem em uma unidade de internação hospitalar e diante do que foi identificado, sugere algumas recomendações para adequar o binômio trabalhador de enfermagem e trabalho nessa unidade e também refere os riscos biológicos aos quais a equipe de enfermagem pode estar exposta em seu ambiente de trabalho. Segundo Marziale (1995), o ambiente hospitalar 
apresenta uma série de riscos decorrentes de agentes biológicos, físicos, psicossociais, químicos e ergonômicos, que devem ser analisados para que se possa caracterizar as condições de trabalho do pessoal de enfermagem.

Algumas pesquisas realizadas em nosso País, fundamentadas no materialismo histórico dialético, buscaram a compreensão do processo saúde-doença vivenciado pelos trabalhadores. Estas pesquisas problematizam a relação trabalhosaúde, colocando no centro da análise o caráter social do processo saúde-doença e a necessidade de entendê-lo na sua articulação com o processo de produção. Nesse enfoque, Silva VEF (1996) reconstrói a relação de determinação entre o trabalho de enfermagem e a saúde dos trabalhadores de enfermagem reproduzindo a construção teórica-metodológica-operacional já validada por Laurell; Noriega (1989). Assim, estas autoras buscam compreender o processo saúdedoença vivenciado pelos trabalhadores de enfermagem de um hospital público e universitário evidenciando as particularidades da relação de determinação trabalho-saúde que se expressam nos trabalhadores de enfermagem, pela exposição às cargas biológicas, físicas, químicas, mecânicas, fisiológicas e psíquicas e verifica que os processos de desgaste do trabalhador de enfermagem são gerados pela diversidade, intensidade e simultaneidade de exposição à essas cargas. Estes processos são explicitados pelos danos biopsíquicos, em suas diferentes formas de expressão apreendidas pela morbidade referida pelos trabalhadores, morbidade registrada nos exames médicos e pelos acidentes de trabalho documentados. Resgata os sinais e sintomas como importantes indicadores do desgaste dos trabalhadores de enfermagem e os ferimentos perfurocortantes e as doenças músculo-articulares como danos característicos do perfil de morbidade destes trabalhadores (SILVA, VEF1996 ).

A pesquisadora Silva (1996) analisou os acidentes de trabalho ocorridos com os trabalhadores de enfermagem na Unidade Centro de Material, bem como os outros riscos de trabalho levantados por estes trabalhadores. Benatti (1997) procurou determinar, na geração de acidente de trabalho, a associação entre a lesão em trabalhadores de enfermagem e os múltiplos fatores de risco decorrentes de suas condições de trabalho e de existência.

Com a preocupante questão relacionada aos riscos ocupacionais associados à exposição do trabalhador, algumas pesquisas foram desenvolvidas com o objetivo de procurar explicar o comportamento de alguns profissionais de enfermagem em sua prática. Baseada no Modelo de Crenças em Saúde (Health Belief Model), Brevidelli (1997) buscou quantificar as crenças individuais que poderiam estar influenciando na prática de reencapar agulhas.

Outros trabalhos, ainda relacionados com o desenvolvimento das atividades na enfermagem, que foram desenvolvidos por Machado et al. (1992), Souza; Vianna (1993) e Laurenti (1996); Sarquis (1999), e também por Sarquis; Felli (2002), abordam uma preocupação com a saúde do trabalhador de enfermagem a partir da constatação do alto risco profissional que esse trabalhador está exposto e a relação com os acidentes de trabalho ocorridos com instrumentos perfurocortantes na sua vivência profissional.

Muitos estudos realizados nas últimas décadas, aqui no Brasil, comprovam a magnitude deste assunto. Basso (1999), estudou os acidentes ocupacionais e constatou a grande exposição a este risco ocupacional entre os trabalhadores de saúde estudados.

Souza (1999), também estudou os acidentes ocupacionais e situações de risco para a equipe de enfermagem em cinco hospitais do município de São Paulo. Constatou que os fatores de risco que interferiram nos acidentes estavam relacionados à organização de trabalho, à falta de conscientização/responsabilidade do empregador e também os fatores relacionados ao trabalhador, como a correta utilização de medidas de biossegurança.

Sarquis (1999), em seu estudo sobre acidentes com instrumentos perfurocortantes encontrou alta freqüência desse tipo de acidente de trabalho, entre os trabalhadores de enfermagem e apontou a não aderência ao uso de equipamento de proteção individual, constatando a grande exposição aos riscos biológicos e às graves doenças como por exemplo a AIDS e a Hepatite B. Estes dados vêm ao encontro de resultados de pesquisas posteriores (SARQUIS; FELLI, 2000; 2002). 
O estudo realizado por Neves (2000), analisou também os acidentes de trabalho ocorridos por agentes biológicos, e encontrou uma grande exposição aos fluidos corpóreos, corroborando com Castro et al. (2000); Zaparoli; Marziale (2003) e Nischide; Benatti (2004) e Mariano et al. (2001).

Neste mesmo contexto, Pivetta, Machado, Araujo, (2001), apresentam em seu estudo um panorama das discussões teóricas sobre o monitoramento biológico na vigilância à saúde, nos casos de exposição a substâncias químicas, em ações de saúde e dos trabalhadores. Ressaltam que o monitoramento biológico e a sua inserção entre as diversas práticas preventivas e o seu uso na saúde pública.

Balsamo (2002), estudou também a exposição ocupacional aos líquidos corporais humanos entre os trabalhadores de saúde. Barbosa; Soler (2003), estudando os afastamentos de trabalho ocorridos entre os trabalhadores de enfermagem. O estudo realizado por Martinez; Paraguai e Latorre (2004), vêm corroborar com os estudos de Barbosa; Soler (2003), comprovando que as condições de trabalho podem desencadear situação de bem estar ou não no ambiente de trabalho.

Lacerda (2000), em seus estudos procurou identificar a ocorrência da exposição por sangue e outras substancias orgânicas entre os trabalhadores de unidade de Centro Cirúrgico, caracterizando suas circunstâncias e correlacionado-as com medidas de controle e prevenção para tais acidentes.

Balsamo (2002), estudou também a exposição ocupacional aos líquidos corporais humanos entre os trabalhadores de saúde. Seu estudo constatou que 58,3\% não receberam as orientações necessárias de como proceder no momento do acidente , e o que é mais significativo ainda é a alta percentagem de $42,8 \%$ que não terminou a quimioprofilaxia que foi indicada, sendo que $23,8 \%$ nem sequer iniciou a quimioprofilaxia que foi indicada, o que registra um percentual de $66,6 \%$ de toda a população estudada que não procedeu corretamente às normas preconizadas. Estes dados são expressivos comprometendo a saúde do trabalhador quando exposto a este tipo de acidente, o que indica a necessidade de revisão e elaboração de estratégias de prevenção dos acidentes com exposição aos líquidos corporais humanos.

Nishide; Benatti ( 2004 ), identificaram os principais riscos ocupacionais a que estão expostos os trabalhadores de enfermagem em UTI (Unidade de Terapia Intensiva). Constataram que os trabalhadores estavam expostos a riscos físicos químicos e biológicos, dependendo da intensidade, natureza e concentração dos trabalhadores, o que pode comprometer seriamente a saúde destes trabalhadores. Afirmam que são necessárias medidas no ambiente de trabalho, além de treinamento, conscientização das práticas e fornecimentos dos dispositivos de segurança aos trabalhadores.

Gir et al. (2004), identificaram os fatores condicionantes da adesão do trabalhador de enfermagem às precauções/isolamento, no momento da assistência ao paciente. Encontraram inadequadas formas de adesão às precauções que podem comprometer a saúde do trabalhador de enfermagem. Os enfermeiros possuem conduta ambivalente frente as situações de riscos, ora priorizando a sua auto proteção, ora valorizando os cuidados de enfermagem em detrimentos das normas de biossegurança e conseqüentemente negligenciando a si próprio.

Carvalho (2004), em seu estudo recente realizado na enfermagem mostrou como a saúde do trabalhador de enfermagem que atua na assistência aos pacientes com alterações psiquiátricas é comprometida. Afirma que estes trabalhadores apresentam maior probabilidade de desenvolver sofrimento psíquico em função do trabalho que realizam.

Sailer (2004), em seu estudo analisou a adesão dos trabalhadores de enfermagem ao tratamento com anti-retrovirais pós exposição ocupacional a materiais biológicos. Identificou a não adesão ao tratamento completo em $42,8 \%$ dos casos. O autor relata a necessidade de implementação nas ações para minimizar tais acidentes, bem como a necessidade de atender o trabalhador considerando os aspectos físicos, pessoais e emocionais.

Considerando a magnitude do contexto e a alta freqüência de exposição dos trabalhadores de enfermagem a todos os riscos e as cargas 
descritos nos estudos, constatamos o quanto podem comprometer a saúde deste profissional.

\section{A evolução da legislação trabalhista}

No início do século XX a Legislação Trabalhista Brasileira priorizava os acidentes causados apenas no ambiente de trabalho. (ANEXO I)

Foi em 1904, no Brasil, o marco inicial para uma legislação que atendesse aos acidentes ocorridos no ambiente de trabalho, mas não houve resultados. Em 1919 surgiu o primeiro decreto legislativo definindo o acidente de trabalho com característica unicausal. Mas somente em 1959 é que foi ampliada a definição de acidente de trabalho e redefinido com característica multicausal.

Foi a partir de 1987, que as principais normas legais davam ênfase aos acidentes de trabalho e as características especificas do trabalho propriamente dito, pois as leis foram elaboradas pelo Ministério do Trabalho.

Com a promulgação da Constituição Federal de 1988 houve melhorias na condição social tanto aos trabalhadores rurais quanto aos trabalhadores urbanos e ficou determinado a obrigatoriedade do seguro contra acidentes de trabalho e a respectiva indenização, o que veio contribuir e acrescentar na melhoria das condições de trabalho até então existentes. A partir de então, estas leis foram regulamentadas pelo Ministério da Saúde, cuja ênfase estava respaldada em princípios que norteiam de uma maneira mais ampla. A assistência à saúde do trabalhador passa a ser de competência do SUS, diante de princípios e diretrizes que o orienta: universalidade, equidade, integralidade das ações e serviços, descentralização e participação social. (BRASIL, 2002). Na seção do SUS que regula o Direito à Saúde está incluído o artigo 200 onde além de outras atribuições refere que compete ao SUS executar as ações de vigilância sanitária e epidemiológica, bem como as de saúde do trabalhador.

A Lei Orgânica da Saúde - LOS n 8080/90, que regulamenta o SUS e suas competências no campo da saúde do trabalhador, considerou o trabalho como importante fator determinante/ condicionante de saúde (BRASIL, 2001).
O artigo $6^{\circ}$ da LOS determina que a realização das ações de saúde do trabalhador sigam os princípios do SUS e recomenda especificamente, a assistência ao trabalhador vítima de acidente de trabalho ou portador de doença profissional ou do trabalho, realização de estudos, pesquisa, avaliação e controle dos riscos e agravos existentes no processo de trabalho; a informação ao trabalhador, sindicatos e empresas sobre riscos de acidentes bem como resultado de fiscalizações, avaliações ambientais, exames admissionais, respeitada a ética (BRASIL, 2002).

Além das leis, no Conselho Nacional de Saúde existe a Comissão Interministerial de Saúde do Trabalhador (CIST), que é uma câmara técnica que realiza assessoria nos assuntos relacionados a saúde do trabalho, através desta foram produzidas e aprovadas várias portarias, entre as quais a Portaria MS n. 119 de 09 de setembro de 1993, que inclui o procedimento "Atendimento específico para Acidente de Trabalho". Na sequência, em 1995 e 1996, duas outras portarias continuam a regulamentação da assistência aos trabalhadores acidentados ou acometidos de doença profissional ou do trabalho, estabelecendo - Programa Integrado de Assistência ao Acidentado do Trabalho - PIAT.(BRASIL,2001).

Outro grande avanço com relação à saúde do trabalhador é a Norma Operacional de Saúde do Trabalhador - NOST-SUS/98, que tem por objetivo definir as atribuições e responsabilidades para orientar e instrumentalizar as ações de saúde do trabalhador urbano e rural, considerando as diferenças entre homens e mulheres, a ser desenvolvidas por Secretarias de Saúde do Estado, Distrito Federal e Municípios.

Dando continuidade e com ênfase na saúde do trabalhador, a Portaria do Ministério da Saúde $\mathrm{n}^{\circ} 3.120$, de $1^{\circ}$ de julho de 1998, aprovou a Instrução Normativa de Vigilância em Saúde do Trabalhador no SUS. Esta portaria é de fundamental importância uma vez que conceitua a Vigilância em saúde do trabalhador como um conjunto de práticas sanitárias, que são articuladas setorialmente e cuja especificidade centra-se na relação da saúde com o ambiente e os processos de trabalho e implica necessariamente na superação das práticas atuais em direção à transformação do modelo assistencial até então vigente (BRASIL, 2001).

A recente portaria $n^{\circ} 1679$ do Ministério da Saúde editada em 2002, traz um enorme avanço 
para os trabalhadores, pois dispõe sobre a Rede Nacional de Assistência a Saúde do Trabalhador (RENAST), que define como organizar as ações de assistência e vigilância nesta área especifica.

Nesse contexto, o Ministério do Trabalho não foi descartado, pois cabe a ele realizar a inspeção e fiscalização das condições e dos ambientes de trabalho em todo o território nacional.

Para cumprir essa atribuição utiliza principalmente o capítulo $\mathrm{V}$ da Consolidação das Leis do Trabalho (CLT), na qual estão as Normas Regulamentadoras.

\section{As Normas Regulamentadoras na Legislação: novos avanços}

A partir da Portaria $\mathrm{n}^{0} 3.214$ de 08 de junho de 1978, foram aprovadas as Normas Regulamentadoras (NRs), relacionadas à Segurança e Medicina do Trabalho, que são de observância obrigatória pelas empresas privadas e públicas e pelos órgãos públicos de administração direta e indireta, bem como pelos órgãos dos poderes legislativo e judiciário que possuam empregados regidos pela CLT (Consolidação das Leis do Trabalho). As NRs foram criadas e ampliadas para a manutenção de condições seguras, bem como potencializar o ambiente de trabalho para a redução ou até mesmo eliminar os riscos existentes, como é o caso da NR5. Uma outra Norma Regulamentadora estabeleceu a obrigatoriedade da elaboração, implementação e a implantação do Programa de Controle Médico de Saúde Ocupacional (PCMSO) contemplado na NR7, que objetiva a promoção e preservação da saúde do conjunto dos seus trabalhadores (BRASIL, 1997).

A NR9 - discorre sobre a obrigatoriedade da elaboração de um programa de prevenção de riscos ambientais no trabalho e a implementação por parte de todos os empregadores e instituições que admitam trabalhadores como empregados, visando preservação da saúde e a integridade dos trabalhadores, através da antecipação, reconhecimento, avaliação e conseqüente controle da ocorrência de riscos ambientais existentes ou que venham a existir no ambiente de trabalho, tendo em consideração a proteção do meio ambiente e dos recursos naturais, contemplado no programa de prevenção de riscos ambientais
(PPRA). (BRASIL, 1997), ressalta ainda, a realização do exercício laboral, o uso de equipamentos de proteção individual - EPI, representando um recurso utilizado para minimizar os riscos à que os trabalhadores estão expostos. (BRASIL, 1997).

A próxima Norma Regulamentadora NR 15 relaciona-se com a exposição dos agentes insalubres encontrados na atividade laboral, diz respeito ao grau de insalubridade existente no ambiente laboral. (Brasil, 1991). As outras normas regulamentadoras contribuíram no processo de trabalho, modificando e atuando nas adaptações e condições de trabalho, como nas características psicofisiológicas (ergonomia), contempladas na NR 17. (BRASIL, 1997).

Aúltima Norma Regulamentadora no final da década de 90, é a NR32, que estabelece diretrizes básicas para implantação de medidas de proteção em relação à segurança e à saúde dos trabalhadores, bem como daqueles que exercem atividades de promoção e assistência à saúde em geral. (BRASIL, 2001).

\section{CONSIDERAÇÕES FINAIS}

É preciso compreender que os assuntos relacionados à saúde do trabalhador de enfermagem não podem ser analisados isoladamente, devem ser associados à questão biológica, às condições de vida no trabalho, bem como aos fatores determinantes para riscos de acidentes, doenças profissionais e do trabalho expressos no processo de trabalho conforme já apresentados por Silva; Massarolo (1998) e Ferreira (2000). Cabe ressaltar que ainda encontrase entre os trabalhadores de enfermagem, um grande número de acidentes de trabalho e doenças ocupacionais. Estes números mostram que a saúde destes trabalhadores está comprometida. Para minimizar tais fatos vários autores recomendam que sejam desenvolvidas estratégias para diminuir tais ocorrências.

Neste sentido, vale ressaltar que gradativamente a Legislação vem abarcando um conjunto de dispositivos que ultrapassam a mera preocupação com a prevenção e o tratamento dos acidentes do trabalho e doenças ocupacionais, contemplando aspectos da saúde relacionados à saúde do trabalhador, na tentativa de dar subsídios 
para que os trabalhadores tenham ambientes de trabalho que comprometam menos sua saúde.

Talvez as estratégias já desenvolvidas pela própria legislação para saúde dos trabalhadores, possam servir como fonte de saber para repensar a saúde do trabalhador de enfermagem e propor alternativas de mudanças para os comprometimentos existentes.

ABSTRACT: This article presents, founded on a literature review, a retrospective on the Brazilian Labor Legislation abn its relations to nursing professionals' health. It was evidenced that there had been an attempt to elaborate a specific legislation on labor accidents since 1904. However, the first law was only passed on in 1919. The afore mentioned law and the ones that have followed it, have changed the conception of labor accident and its implications for workers' health regarding their insertion in the job process. Changes, implications, and adaptations of Labor Legsilation were described: they have aimed to optimize workers' health. Due to legal enforcement, companies' medical teams have had to deem responsible for the results of their occupational programs.

KEY WORDS: Labor Legislation; Workers' health; Nursing.

\section{REFERÊNCIAS}

ALEXANDRE, N. M. C. Contribuição ao estudo das cérvicodorsolombalgias em profissionais de enfermagem. Ribeirão Preto, 1993. Tese [Doutorado] - Escola de Enfermagem da USP.

\section{BALSAMO, A. C. Estudo sobre os acidentes de} trabalho com exposições aos líquidos corporais humanos em trabalhadores da saúde. São Paulo, 2002. Dissertação [Mestrado] - Escola de Enfermagem da USP.

BARBOZA, D. B.; SOLER, Z. A. S. G. Afastamentos do trabalho na enfermagem: ocorrências com trabalhadores de um hospital de ensino. Rev. Latino-Am. Enferm, Ribeirão Preto, v. 11, n. 2, p. 177-183, 2003.

BASSO, M. Acidentes ocupacionais com sangue e outros fluidos corpóreos em profissionais de saúde. São Paulo, 1999. Dissertação [Mestrado] - Escola de Enfermagem da USP.

BENATTI, M. C. C. Acidente de trabalho em um hospital universitário: um estudo sobre a ocorrência e os fatores de risco entre trabalhadores de enfermagem. Ribeirão Preto, 1997. Tese [Doutorado] - Escola de Enfermagem da USP.

BRASIL. Ministério da Saúde. Programa Global da AIDS. Brasília, 2000. 20p.

BRASIL. Ministério da Saúde. Constituição Federativa de 1988. Brasília, 1991.

BRASIL. Ministério da Saúde. Secretaria de Políticas de Saúde. Coordenação Nacional de DST e AIDS. Recomendações para terapia antiretroviral em adultos e adolescentes infectado pelo HIV. Brasília, 2002.

BRASIL, M. V. B.; STEFFENS, F.; LORENZO, D. O perfil do acidentado com material biológico no Hospital de Pronto Socorro. Rev. Hosp. Pronto Socorro, v. 47, n.1, p. 26-33, 2001.

BREVIDELLI, M. M. Exposição ocupacional ao vírus da AIDS e da hepatite $B$ : análise da influência das crenças em saúde sobre a prática de reencapar agulhas. São Paulo, 1997. Dissertação [Mestrado] - Escola de Enfermagem da USP.

CARVALHO, M. B. O trabalho de enfermagem psiquiátrica e os problemas de saúde dos trabalhadores. São Paulo, 2004. Dissertação [Mestrado] - Escola de Enfermagem da USP.

CARVALHO, F. N.; ALMEIDA, L. F.; SABENCA, V. $D$. Biossegurança do trabalhador da área de saúde:análise de fatores de risco para os acidentes biológicos com materiais perfurocortantes. Rev. Enferm. UERJ, Rio de Janeiro, v. 9, n. 1, p.74-75, 2001.

GELBCKE, F. L. Processo saúde - doença e processo de trabalho: a visão dos trabalhadores de enfermagem de um hospital escola. Rio de Janeiro, 1991. Dissertação [Mestrado] Universidade do Rio de Janeiro. 
GIR, E.; TAKAHASHI, R. F.; OLIVEIRA, Mac; NICHIATA, L.; CIOSAK, S. Biossegurança em DST/AIDS: condicionantes da adesão do trabalhador de enfermagem às precauções. Rev. Esc. Enferm USP, São Paulo, v. 38, n. 3, p. 245253, 2004.

LACERDA, R. A. Exposição ocupacional ao sangue e outras substâncias orgânicas de pacientes em unidades de centro cirúrgico de hospitais do Brasil. São Paulo, 2000. Tese [Doutorado] - Escola de Enfermagem da USP.

LAURELL, A. C.; NORIEGA, M. Processo de produção e saúde: trabalho e desgaste operário. São Paulo, HUCITEC, 1989.

LAURENTI, L. O desgaste profissional do enfermeiro. In: CONGRESSO BRASILEIRO DE ENFERMAGEM, 48., São Paulo. Resumo. São Paulo: ABEn - Seção São Paulo, 1996. p. 231.

MACHADO, A. A. et al. Risco de infecção pelo vírus da imunodeficiência humana (HIV) em profissionais de saúde. Rev. Saúde Pública, São Paulo, v. 26, n. 1, p. 54-56, 1992.

MARIANO, C. G. G; EL-FAR, F.; WEY, S. B.; MEDEIROS, E. A. S. Cut and puncture accidents involving health care workers exposed to biological materials. Braz. J. Infect. Dis., Salvador, v. 5, n. 5, p. 235-242, 2001.

MARTINEZ, M. C.; PARAGUAY, A. I. B. B.; LATOBRE, M. R. D. O. Relação entre satisfação com aspectos psicossociais e saúde dos trabalhadores. Rev. Saúde Pública, São Paulo, v. 38, n. 1, p. 55-61, 2004.

MARZIALE, M. H. P. Condições ergonômicas da situação de trabalho do pessoal da enfermagem em uma unidade de internação hospitalar. Ribeirão Preto, 1995. Tese [Doutorado] - Escola de Enfermagem da USP.

MARZIALE, M. H. P.; NISHIMURA, K. Y. N.; FERREIRA, M. M. Riscos de contaminação ocasionados por acidentes de trabalho com material perfuro-cortante entre os trabalhadores de enfermagem. Rev. Latino-Am. Enferm., Ribeirão Preto, v. 12, n. 1, p. 36-42, 2004.

NEVES, S. M. F. M. Estudo dos acidentes de trabalho com material biológico contaminado entre profissionais de saúde no Centro de Pesquisa Hospital Evandro Chagas/Fundação Oswaldo Cruz. Rio de Janeiro, 2000. Dissertação [Mestrado] - Universidade do Estado do Rio de Janeiro.

NISHIDE, V. M.; BENATTI, M. C. C. Riscos ocupacionais entre trabalhadores de enfermagem de uma Unidade de Terapia Intensiva. Rev. Esc. Enferm. USP, São Paulo, v. 38, n. 4, p. 406-414, 2004.

NISHIDE, V. M.; BENATTI, M. C. C.; ALEXANDRE, N. M. C. Ocorrência de acidente de trabalho em uma Unidade de Terapia Intensiva. Rev. LatinoAm. Enferm., Ribeirão Preto, v. 12, n. 2, p. 204211, 2004.

PIVETTA, F. et al. Monitoramento biológico: conceitos e aplicações em saúde pública. Cad. Saúde Pública, Rio de Janeiro, v. 17, n. 3, p. 545554, 2001.

PORTO, C. M. et al. Implantação de um kit para comunicação de acidente do trabalho (kit-cat) como facilitador das ações que envolvem os acidentes com perfurocortantes. Rev. Latino-Am. Enferm., Ribeirão Preto, v. 7, n. 5, p. 121-126, 1999.

RODRIGUES, W. T. B. Avaliação do perfil sorológico para hepatites B e C e exposição ocupacional em cirurgiões-dentistas de Sertãozinho-SP. Ribeirão Preto, 2003. Dissertação [Mestrado] - Faculdade de Medicina de Ribeirão Preto.

SAILER, G. C. Adesão de trabalhadores de enfermagem. São Paulo, 2004. Dissertação [Mestrado] - Escola de Enfermagem da Universidade de São Paulo.

SARQUIS, L. M. M. Acidentes de trabalho com instrumentos perfurocortantes: ocorrência entre 
os trabalhadores de enfermagem. São Paulo, 1999. Dissertação [Mestrado] - Escola de Enfermagem da Universidade de São Paulo.

SARQUIS, L. M. M.; FELLI, V. E. A. O uso do equipamento de proteção individual entre os trabalhadores de enfermagem acidentados com instrumentos perfurocortantes. Rev. Bras. Enfermag., Brasília, v.53, n.4, p. 564-573.out/dez 2000.

SARQUIS, L. M. M.; FELLI, V. E. A. Acidente de trabalho com instrumento perfurocortantes entre os trabalhadores de enfermagem. Rev. Esc. Enferm. USP, São Paulo, v.36, n.3, p. 222-230. 2002.

SILVA, A. Trabalhador de enfermagem na unidade de centro de material e os acidentes de trabalho. São Paulo, 1996. Tese [Doutorado] - Escola de Enfermagem da Universidade de São Paulo.

SILVA, V. E. F. O desgaste do trabalhador de enfermagem: estudo da relação trabalho de enfermagem e saúde do trabalhador. São Paulo, 1996. Tese [Doutorado] - Escola de enfermagem da Universidade de São Paulo.

SOARES, C. B.; REALE, D.; BRITES, C. M. Uso de grupo focal como instrumento de avaliação de programa educacional em saúde. Rev. Esc. Enferm. USP, São Paulo, v.34, n.3, p. 317-22, set. 2000.

SOUZA, M. Conhecimento e aplicação das precauções universais pelos componentes da equipe de enfermagem de um hospital governamental. São Paulo, 1995. Dissertação [Mestrado] - Escola Paulista de Medicina da Universidade Federal de São Paulo.

SOUZA, M.; VIANNA, L. A. C. Incidência de acidentes de trabalho relacionada com a não Utilização das precauções universais. Rev. Bras. Enferm., Brasília, v.46, n.3/4, p.234-244, 1993.

ZAPPAROLI, A. S.; MARZIALE, M. C. Riscos ocupacionais dos trabalhadores que atuam em
Unidades de Suporte Básico e Avançado de Vida em emergências de uma cidade do interior paulista. In: SIMPÓSIO INTERNACIONAL INOVAÇÃO E DIFUSÃO DE CONHECIMENTO EM ENFERMAGEM, 2003, Ribeirão Preto. Ribeirão Preto: Escola de Enfermagem de Ribeirão Preto, 2003. p. 129.

\section{ANEXO I}

Quadro I - Retrospectiva da Legislação Trabalhista e as determinações sobre os acidentes de trabalho, Curitiba, 2004.

\begin{tabular}{|c|c|}
\hline Ano & $\begin{array}{c}\text { Determinações sobre acidentes de trabalho - } \\
\text { Portarias }\end{array}$ \\
\hline 1904 & $\begin{array}{l}\text { Princípio para criar uma legislação especial para } \\
\text { acidentes causados pelo trabalho, porém sem } \\
\text { resultados. (SARQUIS,1999) }\end{array}$ \\
\hline 1919 & $\begin{array}{l}\text { Decreto Legislativo n. } 3724 \\
\text { Definição do acidente de trabalho como adquirido } \\
\text { exclusivamente pelo exercício do trabalho. }\end{array}$ \\
\hline 1934 & $\begin{array}{l}\text { Lei baseada na teoria do risco ocupacional e no } \\
\text { princípio da unicausalidade. CARMO et al(1995) }\end{array}$ \\
\hline 1959 & $\begin{array}{l}\text { Foi ampliada a definição de acidente de trabalho } \\
\text { incluindo as doenças resultantes das condições } \\
\text { especiais em que o trabalho fosse realizado, } \\
\text { excluindo a unicausalidade. A partir desta lei a } \\
\text { responsabilidade pela comunicação do acidente de } \\
\text { trabalho passou a ser feita pelo empregador à } \\
\text { autoridade judiciária, diferente das leis descritas } \\
\text { anteriormente. CARMO et al(1995) }\end{array}$ \\
\hline 1967 & $\begin{array}{l}\text { Lei que desestimulava o trabalhador a mover ações } \\
\text { na justiça e por forçar a obrigatoriedade do seguro } \\
\text { de acidente de trabalho com claro incentivo às } \\
\text { seguradoras privadas, revogada após } 7 \text { meses }\end{array}$ \\
\hline 1967 & $\begin{array}{l}\text { Lei n. } 6.367 \text {, baseada na teoria do risco profissional, } \\
\text { nesta lei foi incluído o acidente de trajeto como } \\
\text { acidente de trabalho. CARMO et al(1995) }\end{array}$ \\
\hline 1976 & $\begin{array}{l}\text { Esta abolia a reparação a danos menores, reduzindo } \\
\text { o valor do auxílio e dos benefícios para acidentes } \\
\text { desprezando as doenças relacionadas com as } \\
\text { condições de trabalho. }\end{array}$ \\
\hline 1977 & $\begin{array}{l}\text { Lei n. } 6514 \text { - Aprovação das Normas } \\
\text { Regulamentadoras (NRs) para o exercício das }\end{array}$ \\
\hline
\end{tabular}




\begin{tabular}{|c|c|}
\hline Ano & $\begin{array}{c}\text { Determinações sobre acidentes de trabalho - } \\
\text { Portarias }\end{array}$ \\
\hline 1978 & $\begin{array}{l}\text { Lei n. } 3214 \text { - Aprovação das Normas } \\
\text { Regulamentadoras (NRs) da Consolidação das Leis } \\
\text { do Trabalho relativas à Segurança e Medicina do } \\
\text { Trabalho e um conjunto de textos suplementares } \\
\text { (leis, portarias e decretos). (BRASIL,1997) } \\
\text { Normas Regulamentadoras: } \\
\text { NR } 5 \text { - Obrigatoriedade da criação Comissão } \\
\text { Interna de Prevenção de Acidente -CIPA } \\
\text { NR } 7 \text { - Implantação do Programa de Controle } \\
\text { Médico de Saúde Ocupacional (PCMSO). } \\
\text { NR } 9 \text { - Programa de Prevenção de Riscos } \\
\text { Ambientais (PPRA). } \\
\text { NR15 - Relacionada ao grau de insalubridade } \\
\text { existente no ambiente laboral. (BRASIL,1997) } \\
\text { NR17- Estabelece parâmetros para a adaptação } \\
\text { das condições de trabalho (ergonomia). }\end{array}$ \\
\hline 1984 & $\begin{array}{l}\text { Decreto n. 89.312- Nova edição da Consolidação } \\
\text { das Leis da Previdência Social (CLPS) referentes à } \\
\text { previdência social urbana, CARMO et al (1995) }\end{array}$ \\
\hline 1991 & $\begin{array}{l}\text { Lei n. } 8213 \text { - Considerava como acidente de trabalho, } \\
\text { tanto no sentido estrito como no sentido amplo os } \\
\text { acidente-tipo, ou macrotrauma, o acidente de trajeto, } \\
\text { as doenças profissionais também denominadas } \\
\text { ergopatias, tecnopatias ou doenças profissionais } \\
\text { típicas, as doenças do trabalho também } \\
\text { denominadas mesopatias ou moléstias profissionais } \\
\text { atípicas, eram aquelas produzidas, desencadeadas } \\
\text { ou agravadas por condições especiais do trabalho. }\end{array}$ \\
\hline 1993 & 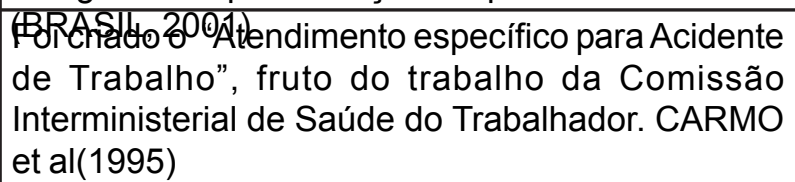 \\
\hline $\begin{array}{c}1995 \\
e \\
1996\end{array}$ & $\begin{array}{l}\text { Continuidade da regulamentação } \\
\text { trabalhadores acidentados ou acor } \\
\text { profissional ou do trabalho, } \\
\text { Programa Integrado de Assistên } \\
\text { do Trabalho- PIAT. (BRASIL, } 200\end{array}$ \\
\hline 1998 & $\begin{array}{l}\text { Portaria MS } 3.120 \text { - Conceitua a Vigilância em saúde } \\
\text { do trabalhador, cuja especificidade centra-se na } \\
\text { relação da saúde com o ambiente e os processos } \\
\text { de trabalho, que engloba estratégias de produção, } \\
\text { que implicam necessariamente a superação das } \\
\text { práticas atuais em direção à transformação do } \\
\text { modelo assistencial. (BRASIL, 2001) }\end{array}$ \\
\hline 2002 & $\begin{array}{l}\text { NR 32- Estabelece diretrizes básicas para } \\
\text { implantação de medidas de proteção em relação à } \\
\text { segurança e à saúde dos trabalhadores, bem como } \\
\text { daqueles que exercem atividades de promoção e } \\
\text { assistência à saúde em geral. }\end{array}$ \\
\hline
\end{tabular}

ENDEREÇO DAS AUTORAS: Av. Iguaçu, 2666 - ap. 1201 Curitiba/PR 80240-030 m.sarquis@brturbo.com 